\title{
Growth, electrical, thermal, mechanical and etching studies on 4-chloroanilinium hydrogen $(2 R, 3 R)$-tartrate monohydrate-an organic NLO single crystal
}

\author{
R. SIVAKUMAR ${ }^{1, *}$, V. NADARAJ ${ }^{2}$ \\ ${ }^{1}$ Department of Chemistry, Hindusthan Institute of Technology, Coimbatore-641032, INDIA. \\ ${ }^{2}$ Department of Chemistry, Tamilnadu College of Engineering, Coimbatore-641659, INDIA.
}

\begin{abstract}
An organic single crystal of 4-chloroanilinium hydrogen (2R,3R)-tartrate monohydrate (4CAHT) was grown by slow evaporation solution growth technique at room temperature. Single crystal XRD study confirmed that the crystal belongs to monoclinic system with the space group P2 $2_{1}$. Powder XRD analysis confirmed the crystalline nature of the compound. The presence of various functional groups in the compound was revealed by FT-IR analysis. UV studies showed the absence of absorption in the entire visible region. To determine the thermal stability of the grown crystals it was subjected to thermogravimetric and differential thermal analyses. Microhardness and etching studies were also carried out for the crystal. The powder second harmonic generation efficiency of 4CAHT was tested by Kurtz and Perry powder technique and the relative SHG efficiency of 4CAHT was found to be 1.44 times greater than that of standard KDP.
\end{abstract}

Keywords: nonlinear optics; TG-DTA; dielectric constant; Vickers hardness

\section{Introduction}

In recent years, the demand for organic nonlinear optical material has been drastically increased because of their potential application in optoelectronic applications, such as optical switches, ultrafast electro-optic modulators, second harmonic generation, frequency mixing and laser spectroscopy [1-4]. Particularly, materials with aromatic rings have focused much attention because of their large hyperpolarizability $(\beta)$, high electronic susceptibility $(\chi(2))$, low cost, high resistance to laser damage, fast response time, ease of synthesis and device fabrication [5-7]. L-tartaric acid is a small organic molecule having large dipole moment, wide transparency range and chiral structure, to form noncentrosymmetric hydrogen bonded crystal structures - an important class of materials exhibiting interesting dielectric, ferroelectric, piezoelectric properties and optical second harmonic generation. Some of them have been extensively used for controlling laser

*E-mail: chemsiva@gmail.com emission and modifying laser radiation. Previously, a series of tartrate compounds were grown and their physiochemical properties were reported [812]. Based on this, 4-chloroanilinium hydrogen (2R,3R)-tartrate monohydrate has been studied. It is one of the compounds whose structure has already been reported [13]. A thorough literature survey revealed that there are no detailed electrical studies available on this material. In the present work, we report, for the first time, its FT-IR, TG/DTA, optical absorption, dielectric, microhardness, etching and powder SHG properties.

\section{Experimental}

\subsection{Crystal growth}

In the present work, 4CAHT crystals were grown by slow evaporation solution growth technique at room temperature. Commercially available 4-chloroaniline (4-CA) $\left(\mathrm{C}_{6} \mathrm{H}_{6} \mathrm{ClN}\right)$ (Himedia, $98 \%)$ and L-tartaric acid (LTA) $\left(\mathrm{C}_{4} \mathrm{H}_{6} \mathrm{O}_{6}\right)$ (Aldrich, $98 \%$ ) were taken in the equimolar ratio and dissolved separately in methanol/water mixed 
solvent and stirred well for about 20 minutes using a magnetic stirrer (Scheme 1).

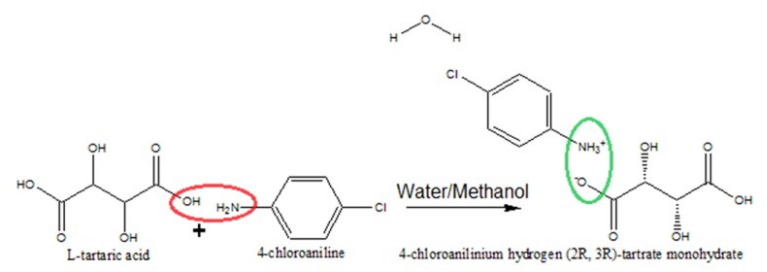

Scheme 1. Reaction scheme of 4CAHT.

Then, the solutions were mixed together and stirred for $1 \mathrm{~h}$ to yield a homogeneous mixture. Then the homogeneous solution was filtered twice using Whatmann filter paper (No. 42) and transferred into a crystallizing vessel. In order to control the evaporation rate, the top of the beaker was covered with a thin plastic sheet and kept at undisturbed state for the slow evaporation process at room temperature. After ten days, good quality crystals with the size of $8 \mathrm{~mm} \times 5 \mathrm{~mm} \times 3 \mathrm{~mm}$ were harvested from the mother solution. A photograph of the as-grown crystal is depicted in Fig. 1.

\section{Results and discussion}

\section{1. $\mathrm{X}$-ray diffraction analysis}

The grown single crystal of the 4CAHT was subjected to single crystal XRD studies using a ENRAF NONIUS CAD-4 X-ray diffractometer with $\mathrm{MoK} \alpha$ radiation $(\lambda=0.7107 \AA)$. The data were collected at room temperature. It has been found that the grown 4CAHT crystal belongs to the monoclinic system with the noncentrosymmetric space group $\mathrm{P} 2{ }_{1}$. The observed lattice dimensions are $\mathrm{a}=7.342 \AA, \mathrm{b}=10.869 \AA, \mathrm{c}=15.967 \AA$, $\beta=97.88^{\circ}$ and volume $=1260.7 \AA^{3}$, which is in good agreement with the earlier reported values [13].

\subsection{FT-IR studies}

The FT-IR spectrum of the 4CAHT crystal was recorded at room temperature in the range of $400 \mathrm{~cm}^{-1}$ to $4000 \mathrm{~cm}^{-1}$ with a Bruker FT-IR 4100 spectrometer using a standard $\mathrm{KBr}$ pellet method. The recorded spectrum is shown in Fig. 2. Table 1

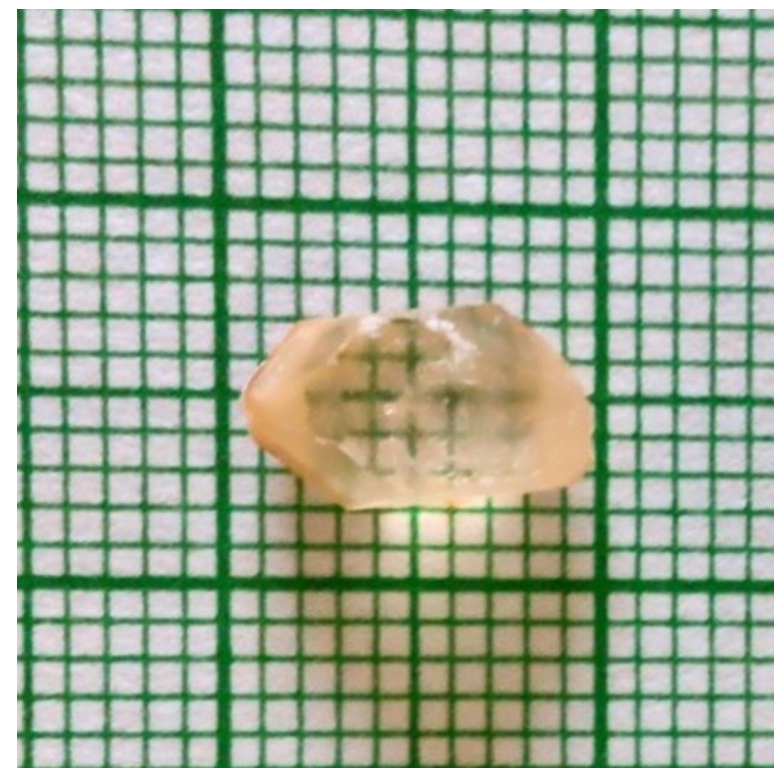

Fig. 1. As-grown crystal of 4CAHT.

shows a comparison of vibration modes present in pure tartaric acid, 4-chloroaniline and 4CAHT.

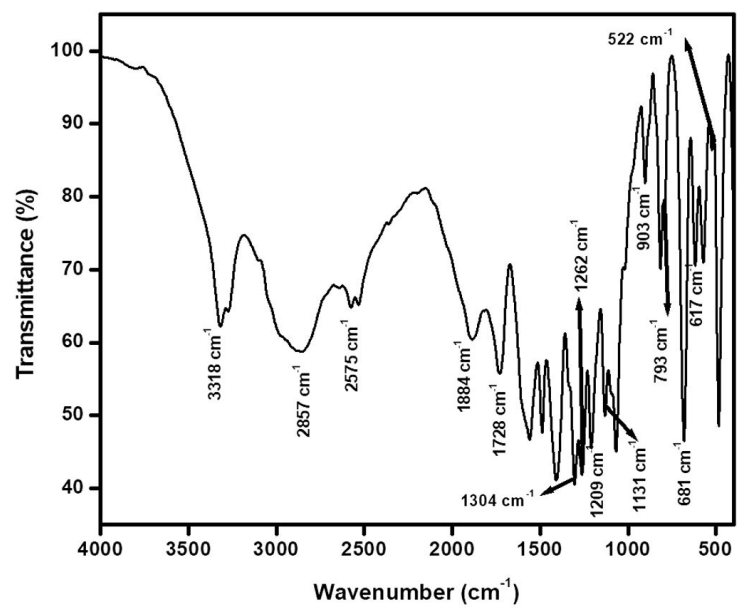

Fig. 2. FT-IR spectrum of 4CAHT.

The peak close to $3318 \mathrm{~cm}^{-1}$ is assigned to $\mathrm{NH}_{3}^{+}$stretching vibration. Also it confirms the presence of hydrogen bonding in the title 4CAHT crystal. The $\mathrm{CH}$ vibration of tartaric acid occurs at $2857 \mathrm{~cm}^{-1}$. The peaks at $2575 \mathrm{~cm}^{-1}$ and $2857 \mathrm{~cm}^{-1}$ are due to the $\mathrm{OH}$ stretching of tartaric acid. A band at $1728 \mathrm{~cm}^{-1}$ is assigned to $\mathrm{C}=\mathrm{O}$, $\mathrm{C}-\mathrm{C}$ and $\mathrm{NH}_{3}^{+}$asymmetric bending vibrations. 
The $\mathrm{NH}_{3}^{+}$rocking and twisting mode have been identified at $1209 \mathrm{~cm}^{-1}$ and $522 \mathrm{~cm}^{-1}$. The $\mathrm{OH} . . \mathrm{O}$ in plane bending mode appears at $1131 \mathrm{~cm}^{-1}$. The $\mathrm{CH}$ bending vibration is observed at $1884 \mathrm{~cm}^{-1}$. A strong symmetric and weak symmetric stretching of ionized carboxylic group (COO-) is observed at $1408 \mathrm{~cm}^{-1}$ and $681 \mathrm{~cm}^{-1}$. COO- in plane bending and wagging modes appear at $793 \mathrm{~cm}^{-1}$ and $617 \mathrm{~cm}^{-1}$. A peak at $1262 \mathrm{~cm}^{-1}$ is due to $\mathrm{C}-\mathrm{O}$ and $\mathrm{CN}$ stretching vibrations. Vibrations at $1304 \mathrm{~cm}^{-1}$ and $903 \mathrm{~cm}^{-1}$ are due to the $\mathrm{C}-\mathrm{C}$ stretching. The in plane deformation of $\mathrm{C}=\mathrm{O}$ occurs at $681 \mathrm{~cm}^{-1}$. C-Cl stretching vibration occurs at $681 \mathrm{~cm}^{-1}$.

\subsection{UV-Vis spectral analysis}

The optical absorption spectrum of the 4CAHT was recorded in the wavelength of $200 \mathrm{~nm}$ to $1100 \mathrm{~nm}$ covering the near UV, visible and NIR regions, by using a Jasco UV-Vis spectrophotometer at room temperature. For optical device applications the crystal should be transparent in the considerable wavelength region. The recorded absorption and transmittance spectra are shown in Fig. 3 and Fig. 4. From the transmittance analysis the lower cut-off wavelength of the crystal was found to be $391 \mathrm{~nm}$. The spectrum exhibits strong absorption at $230 \mathrm{~nm}$ (Fig. 3). It may be due to the $\mathrm{n} \rightarrow \pi^{*}$ transitions in the compound and is assigned to the charge transfer and aromatic conjugations. The charge transfer transition is due to promotion of an electron from HOMO of the donor to LUMO of the acceptor.

Table 1. FT-IR data comparision of pure tartaric acid and 4-chloroaniline with 4CAHT.

\begin{tabular}{cccc}
\hline \multirow{2}{*}{ Vibrations } & \multicolumn{3}{c}{ Wavenumber $\left(\mathbf{c m}^{-1}\right)$} \\
\cline { 2 - 4 } $\mathrm{NH}_{3}{ }^{+}$ & - & $4 \mathrm{CA}$ & $4 \mathrm{CAHT}$ \\
$\mathrm{v}_{\mathrm{as}} \mathrm{NH}_{2}-3500$ & 3318 \\
\hline \hline $\mathrm{CH}$ & - & 3037 & 2857 \\
$\mathrm{C}=\mathrm{O}$ & 1755 & - & 1728 \\
$\mathrm{C}-\mathrm{N}$ & - & 1283 & 1262 \\
$\mathrm{C}-\mathrm{C}$ & - & 1291 & 1304 \\
$\mathrm{C}-\mathrm{Cl}$ & - & 617 & 681 \\
\hline
\end{tabular}

The transmittance in the entire visible region and the absence of absorption between $300 \mathrm{~nm}$ and $1100 \mathrm{~nm}$ is an advantage as it is the desirable property for the materials possessing SHG properties [14].

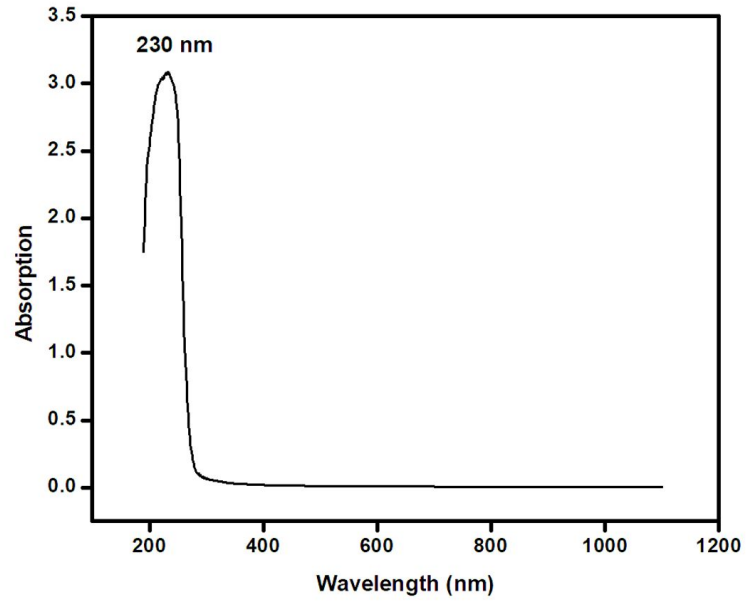

Fig. 3. Optical absorption spectrum of 4CAHT.

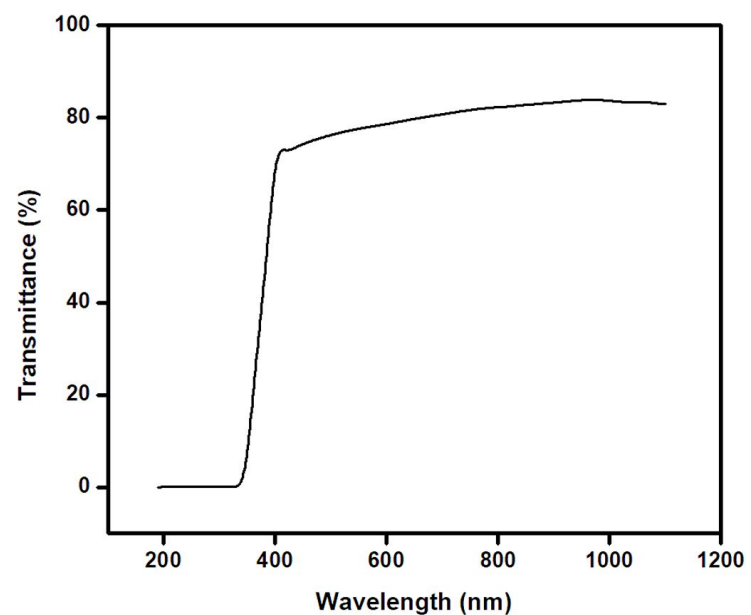

Fig. 4. Optical transmittance spectrum of 4CAHT.

\subsection{Dielectric studies}

Dielectric studies provide useful information regarding the charge transport mechanism in a material, chemical bonding and the polarization mechanism. Good quality single crystals of a size of $6 \mathrm{~mm} \times 5 \mathrm{~mm} \times 2 \mathrm{~mm}$ were chosen for the dielectric measurements. To make a crystal as a dielectric 
medium, electronic grade silver paste was applied on the opposite faces of the crystal. The dielectric measurements were carried out using a Hioki 3532$50 \mathrm{LCR}$ Hi-tester at various frequencies from $50 \mathrm{~Hz}$ to $5 \mathrm{MHz}$ ae different temperatures. The dielectric constant was calculated from the measured capacitance by the given formula:

$$
\varepsilon_{r}=\frac{C d}{\varepsilon_{o} A}
$$

where $\mathrm{C}$ is the capacitance and $\mathrm{d}$ is the thickness of the sample, $\mathrm{A}$ is the cross sectional area of the crystal and $\epsilon_{\mathrm{o}}$ is the free space permittivity $\left(8.854 \times 10^{-12} \mathrm{~F} / \mathrm{m}\right)$. Fig. 5 and Fig. 6 illustrate the dielectric constant and dielectric loss as a function frequency for 4CAHT crystal.

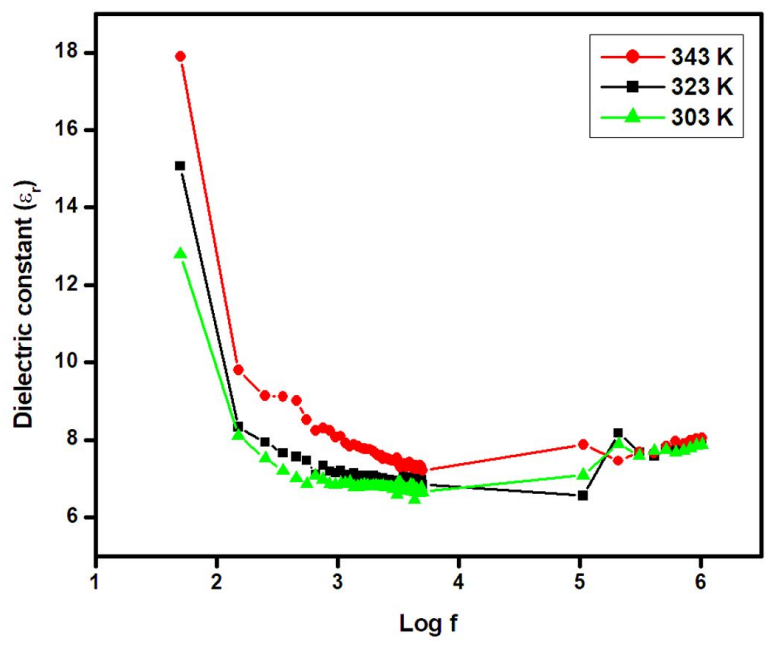

Fig. 5. Dielectric constant vs. $\log f$.

The value of dielectric constant was found to be high at lower frequencies and higher temperature. The higher value at lower frequency may be due to the presence of all four polarization types, namely electronic, ionic, space charge and orientational. The low value at high frequencies can be attributed to the gradual loss of significance of these polarizations. On the other hand, increased dielectric constant at higher temperature may be due to the increase in space charge polarization at the grain boundary interfaces. In accordance with Miller rule, the lower value of dielectric constant at higher frequencies is an appropriate factor

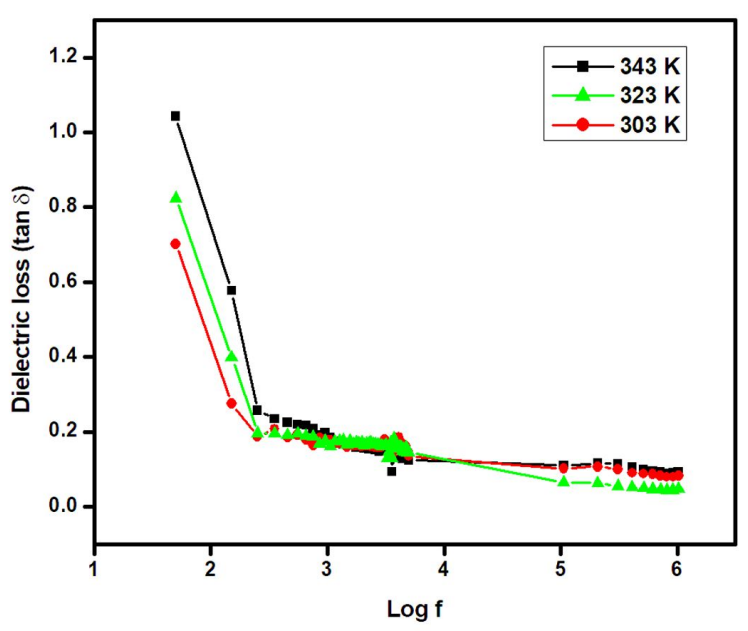

Fig. 6. Dielectric loss vs. $\log \mathrm{f}$.

for the improvement of SHG coefficient [14]. The low value of dielectric loss at higher frequencies suggests that a sample reveals a good optical quality with fewer defects.

\subsection{TG-DTA analysis}

To study the thermal stability, decomposition and melting point of the compound the grown crystals were subjected to the TG/DTA analysis. The thermogravimetric analysis of the 4CAHT crystal was carried out between RT and $600{ }^{\circ} \mathrm{C}$ in a nitrogen atmosphere at a heating rate of $10{ }^{\circ} \mathrm{C} \mathrm{min}-1$ using a STA 1500 thermal analyzer. The TG/DTA spectrum of 4CAHT is depicted in Fig. 7.

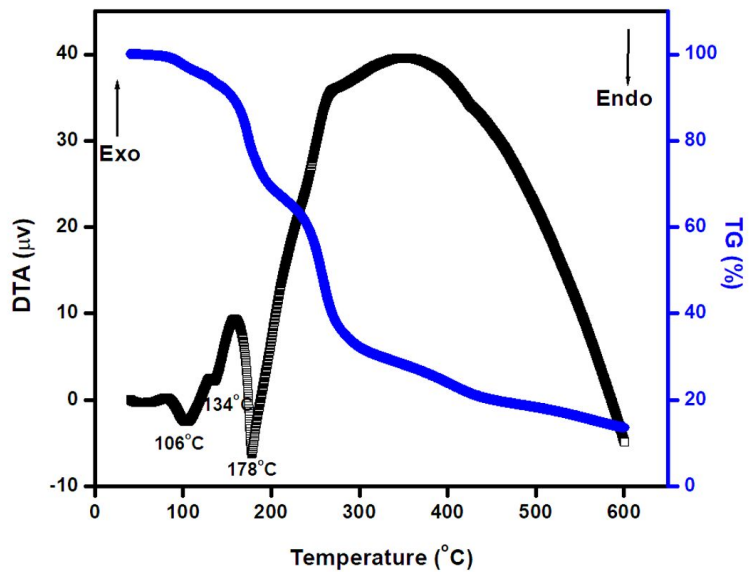

Fig. 7. TG/DTA spectrum of 4CAHT. 
From the graph it is clear that the thermal decomposition of the 4CAHT has taken place in several stages. The sharp endothermic peak at $106{ }^{\circ} \mathrm{C}$ in the DTA curve confirms the presence of water molecules in the compound. The material starts decomposing at $134{ }^{\circ} \mathrm{C}$. A sharp endothermic peak at $178{ }^{\circ} \mathrm{C}$ is attributed to the melting point of the compound which coincides with the literature data. In the TG curve, the weight loss observed between $178{ }^{\circ} \mathrm{C}$ and $600{ }^{\circ} \mathrm{C}$, corresponds to the liberation of volatile substances and gases, such as $\mathrm{CO}, \mathrm{CO}_{2}$, $\mathrm{NO}_{2}, \mathrm{NO}, \mathrm{NH}_{3}$, and $\mathrm{CH}_{2}$ molecules [15]. Finally, a small amount of carbon is present in the residue. From the TG/DTA results it can be concluded that the grown 4CAHT crystals can be used for optoelectronic device applications up to $134{ }^{\circ} \mathrm{C}$.

\subsection{Mechanical studies}

Microhardness is an essential solid state property for understanding the mechanical properties of a crystal. It also plays a key role in the NLO device fabrication. Transparent polished crystals with crack free surfaces were selected for microhardness analysis. Microhardness studies for the grown 4CAHT crystals were carried out using a LEITZ WETZLAR Vickers microhardness pyramidal indenter attached to an incident-light microscope. The grown 4CAHT crystal was properly mounted on the base of the microscope and the indentations were made on the surface by varying the applied load from $25 \mathrm{~g}$ to $100 \mathrm{~g}$. In the present investigation all the measurements were made at room temperature with a constant indentation time of $10 \mathrm{~s}$. Several indentations were made for each load and the average value of the diagonal length was used to calculate the Vickers microhardness number. The Vickers microhardness number was calculated using the following expression:

$$
H_{v}=1.8554\left(P / d^{2}\right)(\mathrm{kg} / \mathrm{mm})^{2}
$$

where $\mathrm{P}$ is the applied load in $\mathrm{g}, \mathrm{d}$ is the diagonal length of the indented impression in $\mu \mathrm{m}$ and 1.8554 is a constant of a geometrical factor for a diamond pyramid. Fig. 8 shows the variation of $\mathrm{H}_{\mathrm{v}}$ as a function of the applied load.

It is clear from the figure that the hardness value increases with an increase in load and the crystal

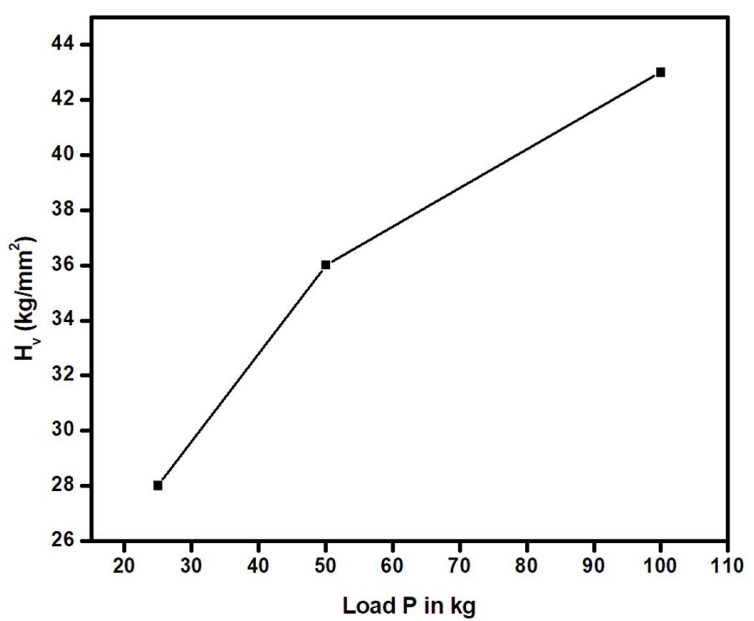

Fig. 8. Hardness vs. applied load.

exhibits the reverse indentation size effect (RISE). An increase in the mechanical strength has a significant effect on NLO device fabrication and processing such as ease in polishing [16] and less wastages due to cracking/breakage while polishing [16, 17]. On further increase in the load above $100 \mathrm{~g}$ micro, cracks were observed, owing to the release of internal stress generated locally by the deformation.

\subsection{Etching studies}

Some features of crystal surfaces, such as growth hillocks, spirals and grain boundaries are essential to study the microstructural imperfections of the crystals. Etching study is an important tool for identification of the crystal defects. Etching studies for the grown 4CAHT crystals were carried out using an OLYMPUS U-TV0.5XC-3 optical microscope in the reflection mode. In the present investigation, methanol was used as an etchant. Fig. 9a to Fig. 9d show the etch pit patterns observed on the flat crystal face of 4CAHT for the etching time of $3 \mathrm{~s}, 8 \mathrm{~s}$ and $10 \mathrm{~s}$, respectively.

The patterns reveal the nucleation and three dimensional growth in a step by step process. Welldefined step-oriented triangular etch patterns are formed at the dislocation sites. The performed study supports the three-dimensional nucleation (3D) mechanism with less dislocation. 

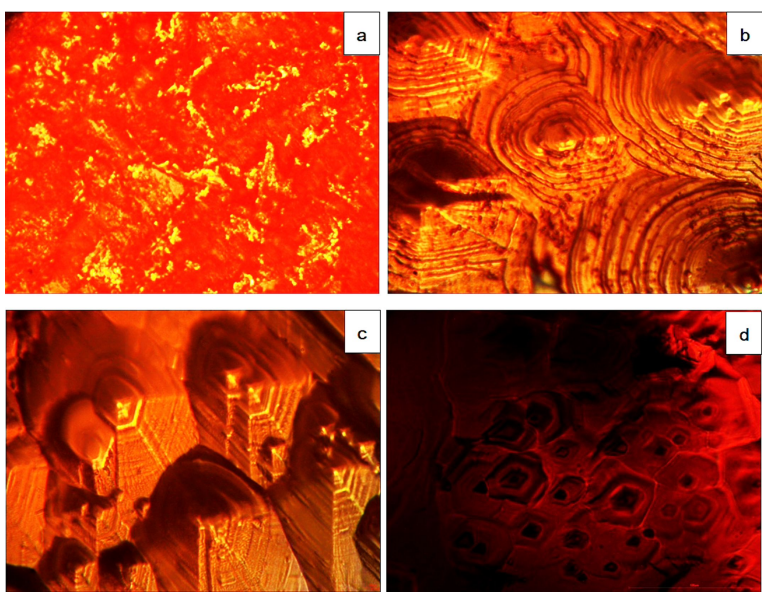

Fig. 9. Etch patterns of 4CAHT crystals at different times (a) $0 \mathrm{~s}$, (b) $3 \mathrm{~s}$, (c) $8 \mathrm{~s}$ and (d) $10 \mathrm{~s}$.

\subsection{Powder SHG measurement}

The powder SHG efficiency of the powdered 4CAHT material was tested using a modified Kurtz and Perry technique [18]. A Q-switched modelocked Nd:YAG laser beam with the wavelength of $1064 \mathrm{~nm}$ was used as an optical source for the SHG measurements. An input power of $4 \mathrm{~mJ} /$ pulse, pulse width of $8 \mathrm{~ns}$ and a repetition rate of $10 \mathrm{~Hz}$ were used. A grown 4CAHT crystal was ground into a powder with particle size of $150 \mu \mathrm{m}$ and packed in a microcapillary tube. Microcrystalline KDP with the same particle size was used as the reference for SHG measurements. The SHG behavior of the 4CAHT was confirmed from the emission of green radiation $(532 \mathrm{~nm})$. The green light intensity was measured using a photomultiplier tube and displayed on a storage oscilloscope. The SHG signals of $13 \mathrm{mV}$ and $9 \mathrm{mV}$ were obtained for 4CAHT and KDP. Thus, the SHG efficiency of the 4CAHT is 1.44 times higher than that of the reference KDP. SHG efficiency of the 4CAHT compared with some known organic crystals and is given in Table 2.

\section{Conclusions}

Organic single crystals of 4-chloroanilinium hydrogen $(2 \mathrm{R}, 3 \mathrm{R})$-tartrate monohydrate with a good optical quality were grown from an aqueous solution at room temperature. Single crystal XRD
Table 2. Comparison of SHG efficiency of 4CAHT.

\begin{tabular}{ccc}
\hline Compound & $\begin{array}{c}\text { SHG efficiency } \\
\text { (Reference KDP) }\end{array}$ & Ref \\
\hline \hline PTM & 0.5 & {$[19]$} \\
LALT & 1.5 & {$[20]$} \\
HMT & 2.0 & {$[21]$} \\
LPAPN & 1.2 & {$[22]$} \\
4CAHT & 1.44 & Present Work \\
\hline
\end{tabular}

confirmed that the 4CAHT crystallized in monoclinic system. The functional groups present in the compound were studied by FT-IR. Maximum absorption value at $230 \mathrm{~nm}$ was revealed by optical studies. The TG-DTA analysis showed that the crystal can be used for device applications up to $134{ }^{\circ} \mathrm{C}$. Low value of dielectric constant and dielectric loss confirmed the suitability of these crystals for optoelectronics applications. The mechanical strength of the crystals was investigated using Vickers microhardness tester and it was found that 4CAHT exhibits reverse indentation size effect. The powder SHG efficiency was 1.44 times greater than that of standard KDP. The microhardness analysis confirmed the soft nature of the crystal. Etching studies revealed the triangular etch pits with low number of dislocations. Thus, the performed studies showed that the 4CAHT is a suitable candidate for NLO applications.

\section{References}

[1] Sornamurthya B.M., Peramaiyan G., Rekha P., Arunkumar A., Mohan Kumar R., ManivanNAN V., Optik, 125 (2014), 5695.

[2] Bincy I.P., Gopalakrishnan R., J. Cryst. Growth, 402 (2014), 22.

[3] Pandi P., Peramaiyan G., Krishna Kumar M., Mohan Kumar R., Jayavel R., Spectrochim. Acta A, 88 (2012), 77.

[4] Sudharsana N., Subramanian G., KrishnakuMar V., Nagalakshmi R., Spectrochim. Acta A, 97 (2012), 798.

[5] KanNAN V., ThiRUpUgalmani K., BRAHADEESWARAN S., J. Mol. Struct., 1049 (2013), 268.

[6] Babu B., Chandrasekaran J., BalaprabHAKARAN S., Optik, 125 (2014), 3005.

[7] Chandrasekaran J., Balaprabhakaran S., BABU B., Optik, 124 (2013), 4296. 
[8] Meena K., Muthu K., Meenatchi V., RAJASEKAR M., Bhagavannarayana G., MEENAKSHISUNDARAM S.P., Spectrochim. Acta A, 124 (2014), 663.

[9] Moovendaran K., Bikshandarkoil R. SRIniVASAN, KALYANA SUNDAR J., MARTIN BRITTO Dhas S.A., Natarajan S., Spectrochim. Acta A, 92 (2012), 388.

[10] Mohana Priyadarshini K., Chandramohan A., Anandha Babu G., Ramasamy P., Solid State Sci., 28 (2014), 95

[11] Peramaiyan G., Pandi P., Sornamurthy B.M., Bhagavannarayana G., Mohan Kumar R., Spectrochim. Acta A, 95 (2012), 310.

[12] Joseph Daniel D., Ramasamy P., Mater. Res. Bull., 47 (2012), 708.

[13] Smith G., Wermuth U.D., White J.M., Acta Cryst. Sec. E, 63 (2007), o3432.

[14] Balaprabhakaran S., Chandrasekaran J., Babu B., Thirumurugan R., Anitha K., Spectrochim. Acta A, 136 (2015), 700.

[15] Bhagavannarayana G., Riscob B., Mohd. SHAKIR, Mater. Chem. Phys., 126 (2011), 20.
[16] Senthil Pandian M., Balamurugan N. Ganesh V., Raja Shekar P.V., Krishan Rao K., RAMASAMY P., Mater. Lett., 62 (2008), 3830.

[17] Senthil Pandian M., Pattanaboonmee N., RAMASAMy P., Manyum P., J. Cryst. Growth, 314 (2011), 207.

[18] Kurtz S.K., Perry T.T., J. Appl. Phys., 39 (1968), 3798.

[19] Peramaiyan G., Pandi P., Sornamurthy B.M., Bhagavannarayana G., Mohan Kumar R., Spectrochim. Acta Part A, 95 (2012), 310.

[20] Vivek P., Murugakoothan P., Optik, 124 (2013), 3510.

[21] Babu B., Chandrasekaran J., BalaprabHAKARAN S., Mater. Sci.-Poland, 32 (2014), 164.

[22] Prakash M., Lydia Caroline M., Geetha D., Spectrochim. Acta Part A, 108 (2013), 32.

Received 2016-06-18 Accepted 2019-04-23 